\title{
CD19CAR-CD28-CD3zeta-EGFRt-expressing Tcm-enriched T-lymphocytes
}

National Cancer Institute

\section{Source}

National Cancer Institute. CD19CAR-CD28-CD3zeta-EGFRt-expressing Tcm-enriched Tlymphocytes. NCl Thesaurus. Code C133072.

A preparation of genetically modified central memory $(T \mathrm{~cm})$ enriched $\mathrm{T}$-cells transduced with a replication incompetent lentiviral vector expressing a chimeric antigen receptor (CAR), containing a CD28 signaling domain fused to both CD3 zeta, which targets the CD19 antigen, and a truncated form of the human epidermal growth factor receptor (EGFRt), with potential immunostimulating and antineoplastic activities. Upon intravenous administration, CD19CAR-CD28-CD3zeta-EGFRt-expressing Tcm-enriched T cells are directed to CD19-expressing tumor cells, thereby inducing a selective toxicity in CD19expressing tumor cells. CD19 antigen is a B-cell specific cell surface antigen expressed in all B-cell lineage malignancies. Devoid of both ligand binding domains and tyrosine kinase activity, EGFRt both facilitates in vivo detection of the administered T-cells and can promote elimination of those cells upon a cetuximab-induced antibody dependent cellular cytotoxicity response. The costimulatory signaling domain enhances proliferation of $\mathrm{T}$ cells and antitumor activity. 